\title{
Evaluation of relationship between chronological age cervical vertebrae maturation index method and canine calcification stages for the assessment of optimal treatment timing in orthodontic patients
}

\author{
Abhimanyu Rohmetra ${ }^{1}$, Ankita Jaiswal ${ }^{2, *}$, Ishita ${ }^{3}$, Niharika Gupta ${ }^{4}$, Rohit Kulshrestha ${ }^{5}$ \\ ${ }^{1}$ Consultant, ${ }^{2,5}$ Senior Lecturer, ${ }^{3}$ UG Student, ${ }^{4}$ MDS Student, ${ }^{1-3,5}$ Dept. of Orthodontics and Dentofacial Orthopedics, ${ }^{4}$ Dept. of Oral and \\ Maxillofacial Surgery, ${ }^{2}$ Vyas Dental College, Jodhpur, Rajasthan, ${ }^{3}$ IDS Sehora, Jammu, Jammu and Kashmir, ${ }^{4}$ DAV Dental \\ College, Yamunanagar, Haryana, ${ }^{5}$ Terna Dental College and Hospital Navi Mumbai, Maharashtra, India
}

*Corresponding Author: Ankita Jaiswal

Email: dr.ortho.aj@gmail.com

\begin{abstract}
Introduction: The study was undertaken to evaluate the reliability of cervical vertebrae as skeletal age maturation in response to chronological age and evaluate the relationship between DEMIRIJAN system of mandibular canine calcification and cervical vertebral maturation as a clinical method for skeletal maturation indicator.

Materials and Methods: 120 children (60 females and 60 males) were randomly selected in the age range of 8-14 years.

Results: $23.3 \%$ of males showed E stage of (canine calcification stage) CCS and stage II of cervical vertebral maturation (CVM), $16.6 \%$ showed F stage of CCS and stage III of CVM, 13.3\% showed stage G of CCS and Stage III of CVM 8.3\% showed stage G of CCS and stage IV of CVM. 13.3\% of females showed E stage of CCS and stage II of CVM, 13.3\% showed F stage of CCS and stage III of CVM, $16.67 \%$ showed stage G of CCS and Stage III of CVM, 15\% shows stage G of CCS and stage IV of CVM,.

Conclusions: The correlation values between the Chronological age, dental calcification stages and cervical vertebrae maturation method were high. Attaining of maturity in canine calcification and cervical vertebrae maturational stages was ahead in females when compared to males.
\end{abstract}

Keywords: Cervical vertebrae, Cephalometrics, Canine calcification.

\section{Introduction}

Biological maturation is a comprehensive concept, which is often conceived as a series of successive transformations through time leading to the attainment of the adult state. Maturity indicates a general concept at any specified age or level during the process of development.

The degree of maturity has been determined by various indicators like chronological age, bone development, height, weight dental development and sexual maturation characteristics. Differences in the development among children of the same chronological age have led to the concept of physiologic age, which is a reflection of the degree of skeletal and dental maturation. Beside cervical vertebrae indicator \& hand wrist radiograph as skeletal maturity indicator the Demirijan ${ }^{1}$ system of tooth calcification has been utilized for physiologic age estimation. Historically, there have been two criteria for dental age assessment: clinical eruption or emergence of teeth and degree of tooth development or formation. Tooth formation is superior to tooth emergence because emergence is governed by several environmental factors; while development of a tooth occurs in a normal histologic pattern unaffected by environmental factors. ${ }^{2}$

As the lateral Cephalogram, Orthopantogram, IOPA xrays (upper and lower anterior teeth) these $\mathrm{X}$-ray are must for all patient starting orthodontic treatment, The need to take an additional hand-wrist radiograph for assessing skeletal age can be eliminated and the patient can be saved from additional exposure and cost of the x-ray

The relationship between dental and skeletal ages correlates the two ages to diagnose skeletal maturity for starting orthodontic treatment. They can be used interchangeably as maturity indicators. However recent reports show that skeletal maturation may vary over time, between ethnic subgroups, or between children in different geographical locations. ${ }^{3}$

This study was undertaken to evaluate the reliability of cervical vertebrae as skeletal age maturation in response to chronological age and evaluate the relationship between DEMIRIJAN ${ }^{1}$ system of mandibular canine calcification and cervical vertebral maturation as a clinical method for skeletal maturation indicator in India.

\section{Materials and Methods}

A total of 120 school children (60 females and 60 males) were randomly selected in the age range of 8-14 years.

Grouping of sample was done upon age basis as follows:

$\begin{array}{lll}\text { Group - I } & = & 8-9 \text { Years } \\ \text { Group -II } & = & 9-10 \text { Years } \\ \text { Group -III } & = & 10-11 \text { Years } \\ \text { Group-IV } & = & 11-12 \text { Years } \\ \text { Group-V } & = & 12-13 \text { Years } \\ \text { Group-VI } & = & 13-14 \text { Years }\end{array}$

Each group will contain 10 boys and 10 girls and data will be collected by using standarized technique of lateral cephalometry and dental of oral periapical radiograph of mandibular left permanent canine.

Selection of Subjects: After preliminary screening, 120 subjects were selected using the selection criteria.

The criteria of selection were as follows: 
1. Well-nourished subjects who were free of any known illness.

2. No previous study of any orthodontic treatment.

3. Absence of dental anomalies.

\section{Materials and Equipment}

1. Kodak $8 \times 10$ inches (Cephalograms and cassette)

2. Intra oral periapical radiograph film ( $\operatorname{size} 0=22-35 \mathrm{~mm}$, size $2=32-41 \mathrm{~mm}$ )

3. Radiographic viewer

4. Matter acetate tracing paper

5. $0.5 \mathrm{~m}$ diameter mechanical lead pencil

An intra oral periapical radiograph and lateral cephalogram were taken for each child.

Assessment of Maturity: All assessments were performed in a darkened room with a radiographic illuminator to ensure contrast enhancement of the bone and tooth images.

The Dental Method: The dental calcification stages were evaluated using the Demirjian's method (Table 1).

Dental intra oral periapical radiograph of mandibular left permanent canine were assessed by using the Demirjian's ${ }^{1}$ method. Canine was given a stage of development designated with letters $\mathrm{A}$ to $\mathrm{H}$. The same letter rating for different teeth received a different weighted score. The weighted score from each tooth was read from gender specific tables (Table 2). These scores were added together to give the total maturity score, which was converted to a dental age by referring the table given by Demirjian ${ }^{1}$ et al. in 1973 (Table 3a and 3b).

Stages in cervical vertebrae development as described by Lamparski ${ }^{4}$ and modified by Hassel and farman. ${ }^{5}$
CVMS 1: The lower borders of all the three vertebrae are flat, with the possible exception of a concavity at the lower border of $\mathrm{C} 2$ in almost half of the cases. The bodies of both $\mathrm{C} 3$ and $\mathrm{C} 4$ are trapezoid in shape (the superior border of the vertebral body is tapered from posterior to anterior). The peak in mandibular growth will occur not earlier than one year after this stage.

CVMS II: Concavities at the lower borders of both $\mathrm{C} 2$ and C3 are present. The bodies of C3 and C4 may be either trapezoid or rectangular in shape. The peak in mandibular growth will occur one year after this stage.

CVMS III: Concavities at the lower border of $\mathrm{C} 2, \mathrm{C} 3$ and $\mathrm{C} 4$ now are present. The bodies of both $\mathrm{C} 3$ and $\mathrm{C} 4$ are rectangular horizontal in shape. The peak in mandibular growth has occurred within one or two years before this stage.

CVMS IV: The concavities at the lower borders of C2, C3 and $\mathrm{C} 4$ now are present. At least one of the bodies of $\mathrm{C} 3$ and $\mathrm{C} 4$ is squared in shape. If not squared, the body of the other cervical vertebra still is rectangular horizontal. The peak in mandibular growth has occurred not later than one year before this stage.

CVMS V: The concavities at the lower borders of $\mathrm{C} 2, \mathrm{C} 3$ and $\mathrm{C} 4$ still are evident. At least one of the bodies of $\mathrm{C} 3$ and C4 is rectangular vertical in shape. If not rectangular vertical, the body of the other cervical vertebra is squared. The peak in mandibular growth has occurred not later than two years before this stage.

Table 1: Demirjian's method ${ }^{1}$

\begin{tabular}{|l|l|}
\hline Stage & Description \\
\hline A & $\begin{array}{l}\text { In both uniradicular and multiradicular teeth, a beginning of calcification is seen at the superior level of the } \\
\text { crypt in the form of an inverted cone or cones. There is no fusion of these calcified points. }\end{array}$ \\
\hline B & $\begin{array}{l}\text { Fusion of the calcified points forms one or several cusps, which unite to give a regularly outlined occlusal } \\
\text { surface. }\end{array}$ \\
\hline C & $\begin{array}{l}\text { a. } \quad \text { Enamel formation is complete at the occlusal surface. Its extension and convergence towards the cervical } \\
\text { region is seen. } \\
\text { b. The beginning of a dentinal deposit is seen. } \\
\text { c. The outline of the pulp chamber has a curved shape at the occlusal border. }\end{array}$ \\
\hline D & $\begin{array}{l}\text { a. The crown formation is completed down to the cementoenamel junction. } \\
\text { b. The superior border of the pulp chamber in the uniradicular teeth has a definite curved form, being } \\
\text { concave towards the cervical region. The projection of the pulp horns if present, gives an outline shaped } \\
\text { E }\end{array}$ \\
c. Bike an umbrella top. In molars the pulp chamber has a trapezoidal form. \\
$\begin{array}{l}\text { Uniradicular teeth: } \\
\text { a. The walls of the pulp chamber now form straight lines, whose continuity is broken by the presence of the } \\
\text { pulp horn, which is larger than in the previous stage. } \\
\text { b. The root length is less than the crown height. }\end{array}$ \\
$\begin{array}{l}\text { Molars: } \\
\text { a. Initial formation of the radicular bifurcation is seen in the form of either a calcified point or a semi-lunar } \\
\text { shape. } \\
\text { b. The root length is still less than the crown height. }\end{array}$ \\
$\begin{array}{l}\text { Uniradicular teeth: } \\
\text { a. The walls of the pulp chamber now form a more or less isosceles triangle. The apex ends in a funnel } \\
\text { shape. }\end{array}$ \\
\hline
\end{tabular}

International Journal of Oral Health Dentistry, October-December, 2018;4(4):214-221 


\begin{tabular}{|c|c|}
\hline & $\begin{array}{l}\text { b. The root length is equal to or greater than the crown height. } \\
\text { Molars: } \\
\text { a. The calcified region of the bifurcation has developed further down from its semi-lunar stage to give the } \\
\text { roots a more definite and distinct outline with funnel shaped endings. } \\
\text { b. The root length is equal to or greater than the crown height. }\end{array}$ \\
\hline $\mathrm{G}$ & a. The walls of the root canal are now parallel and its apical end is still partially open (Distal root in molars). \\
\hline $\mathrm{H}$ & $\begin{array}{l}\text { The apical end of the root canal is completely closed (Distal root in molars). } \\
\text { The periodontal membrane has a uniform width around the root and the apex. }\end{array}$ \\
\hline
\end{tabular}

Table 2: Self-weighted scores for dental stages 7 teeth (mandibular left side)

\begin{tabular}{|c|c|c|c|c|c|c|c|c|c|}
\hline \multirow[t]{2}{*}{ Tooth } & \multirow[t]{2}{*}{ Stage } & \multicolumn{8}{|c|}{ Boys } \\
\hline & & $\mathrm{A}$ & $\mathrm{B}$ & $\mathrm{C}$ & $\mathrm{D}$ & $E$ & $\mathrm{~F}$ & $G$ & $\mathrm{H}$ \\
\hline $\mathrm{M}_{2}$ & 0 & 2.1 & 3.5 & 5.9 & 10.1 & 12.5 & 13.2 & 13.6 & 15.4 \\
\hline $\mathrm{M}_{1}$ & 0.0 & & & 0.0 & 8.0 & 9.6 & 12.3 & 17.0 & 19.3 \\
\hline $\mathrm{PM}_{2}$ & & 1.7 & 3.1 & 5.4 & 9.7 & 12.0 & 12.8 & 13.2 & 14.4 \\
\hline $\mathrm{PM}_{1}$ & 0.0 & & 0.0 & 3.4 & 7.0 & 11.0 & 12.3 & 12.7 & 13.5 \\
\hline $\mathrm{C}$ & & & & 0.0 & 3.5 & 7.9 & 10.0 & 11.0 & 11.9 \\
\hline $\mathrm{I}_{2}$ & & & & & 3.2 & 5.2 & 7.8 & 11.7 & 13.7 \\
\hline $\mathrm{I}_{1}$ & & & & & 0.0 & 1.9 & 4.1 & 8.2 & 11.8 \\
\hline \multirow[t]{2}{*}{ Tooth } & Stage & \multicolumn{8}{|c|}{ Girls } \\
\hline & & $\mathrm{A}$ & B & $\mathrm{C}$ & $\mathrm{D}$ & $E$ & $\mathrm{~F}$ & G & $\mathrm{H}$ \\
\hline $\mathrm{M}_{2}$ & 0 & 2.7 & 3.9 & 6.9 & 11.1 & 13.5 & 14.2 & 14.5 & 15.6 \\
\hline $\mathrm{M}_{1}$ & 0.0 & & & 0.0 & 4.5 & 6.2 & 9.0 & 14.0 & 16.2 \\
\hline $\mathrm{PM}_{2}$ & & 1.8 & 3.4 & 6.5 & 10.6 & 12.7 & 13.5 & 13.8 & 14.6 \\
\hline $\mathrm{PM}_{1}$ & 0.0 & & 0.0 & 3.7 & 7.5 & 11.8 & 13.1 & 13.4 & 14.1 \\
\hline $\bar{C}$ & & & & 0.0 & 3.8 & 7.3 & 10.3 & 11.6 & 12.4 \\
\hline $\mathrm{I}_{2}$ & & & & 0.0 & 3.2 & 5.6 & 8.0 & 12.2 & 14.2 \\
\hline $\mathrm{I}_{1}$ & & & & & 0.0 & 2.4 & 5.1 & 9.3 & 12.9 \\
\hline
\end{tabular}

Table 3a: Conversion of maturity score to dental age 7 teeth (mandibular left side) - boys

\begin{tabular}{|l|c|c|c|c|c|c|c|}
\hline \multicolumn{1}{|c|}{ Age } & Score & Age & Score & Age & Score & Age & Score \\
\hline 3.0 & 12.4 & 7.0 & 46.7 & 11.0 & 92.0 & 15.0 & 97.6 \\
\hline .1 & 12.9 & .1 & 48.3 & .1 & 92.2 & .1 & 97.7 \\
\hline .2 & 13.5 & .2 & 50.0 & .2 & 92.5 & .2 & 97.8 \\
\hline .3 & 14.0 & .3 & 52.0 & .3 & 92.7 & .3 & 97.8 \\
\hline .4 & 14.5 & .4 & 54.3 & .4 & 92.9 & .4 & 97.9 \\
\hline .5 & 15.0 & .5 & 56.8 & .5 & 93.1 & .5 & 98.0 \\
\hline .6 & 15.6 & .6 & 59.6 & .6 & 93.3 & .6 & 98.1 \\
\hline .7 & 16.2 & .7 & 62.5 & .7 & 93.5 & .7 & 98.2 \\
\hline .8 & 17.0 & .8 & 66.0 & .8 & 93.7 & .8 & 98.2 \\
\hline .9 & 17.6 & .9 & 69.0 & .9 & 93.9 & .9 & 98.3 \\
\hline 4.0 & 18.2 & 8.0 & 71.6 & 12.0 & 94.0 & 16.0 & 98.4 \\
\hline .1 & 18.9 & .1 & 73.5 & .1 & 94.2 & & \\
\hline .2 & 19.7 & .2 & 75.1 & .2 & 94.4 & & \\
\hline .3 & 20.4 & .3 & 76.4 & .3 & 94.5 & & \\
\hline .4 & 21.0 & .4 & 77.7 & .4 & 94.6 & & \\
\hline .5 & 21.7 & .5 & 79.0 & .5 & 94.8 & & \\
\hline .6 & 22.4 & .6 & 80.2 & .6 & 95.0 & & \\
\hline .7 & 23.1 & .7 & 81.2 & .7 & 95.1 & & \\
\hline .8 & 23.8 & .8 & 82.0 & .8 & 95.2 & & \\
\hline .9 & 24.6 & .9 & 82.8 & .9 & 95.0 & & \\
\hline 5.0 & 25.4 & 9.0 & 83.6 & 13.0 & 95.6 & & \\
\hline .1 & 26.2 & .1 & 84.3 & .1 & 95.7 & & \\
\hline .2 & 27.0 & .2 & 85.0 & .2 & 95.8 & & \\
\hline .3 & 27.8 & .3 & 85.6 & .3 & 95.9 & & \\
\hline .4 & 28.6 & .4 & 86.2 & .4 & 96.0 & & \\
\hline
\end{tabular}




\begin{tabular}{|l|c|c|c|c|c|c|c|}
\hline .5 & 29.5 & .5 & 86.7 & .5 & 96.1 & & \\
\hline .6 & 30.3 & .6 & 87.2 & .6 & 96.2 & & \\
\hline .7 & 31.1 & .7 & 87.7 & .7 & 96.3 & & \\
\hline .8 & 31.8 & .8 & 88.2 & .8 & 96.4 & & \\
\hline .9 & 32.6 & .9 & 88.6 & .9 & 96.5 & & \\
\hline 6.0 & 33.6 & 10.0 & 89.0 & 14.0 & 96.6 & & \\
\hline .1 & 34.7 & .1 & 89.3 & .1 & 96.7 & & \\
\hline .2 & 35.8 & .2 & 89.7 & .2 & 96.8 & & \\
\hline .3 & 36.9 & .3 & 90.0 & .3 & 96.9 & & \\
\hline .4 & 38.0 & .4 & 90.3 & .4 & 97.0 & & \\
\hline .5 & 39.2 & .5 & 90.6 & .5 & 97.1 & & \\
\hline .6 & 40.6 & .6 & 91.0 & .6 & 97.2 & & \\
\hline .7 & 42.0 & .7 & 91.3 & .7 & 97.3 & & \\
\hline .8 & 43.6 & .8 & 91.6 & .8 & 97.4 & & \\
\hline .9 & 45.1 & .9 & 91.8 & .9 & 97.5 & & \\
\hline
\end{tabular}

Table 3b: Conversion of maturity score to dental age 7 teeth (mandibular left side) - girls

\begin{tabular}{|l|c|c|c|c|c|c|c|}
\hline \multicolumn{1}{|c|}{ Age } & Score & Age & Score & Age & Score & Age & Score \\
\hline 3.0 & 13.7 & 7.0 & 51.0 & 11.0 & 94.5 & 15.0 & 99.2 \\
\hline .1 & 14.4 & .1 & 52.9 & .1 & 94.7 & .1 & 99.3 \\
\hline .2 & 15.1 & .2 & 55.5 & .2 & 94.9 & .2 & 99.4 \\
\hline .3 & 15.8 & .3 & 57.8 & .3 & 95.1 & .3 & 99.4 \\
\hline .4 & 16.6 & .4 & 61.0 & .4 & 95.3 & .4 & 99.5 \\
\hline .5 & 17.3 & .5 & 65.0 & .5 & 95.4 & .5 & 99.6 \\
\hline .6 & 18.0 & .6 & 68.0 & .6 & 95.6 & .6 & 996 \\
\hline .7 & 18.8 & .7 & 71.8 & .7 & 95.8 & .7 & 99.7 \\
\hline .8 & 19.5 & .8 & 75.0 & .8 & 96.0 & .8 & 99.8 \\
\hline .9 & 20.3 & .9 & 77.0 & .9 & 96.2 & .9 & 99.9 \\
\hline 4.0 & 21.0 & 8.0 & 78.8 & 12.0 & 96.3 & 16.0 & 100.0 \\
\hline .1 & 21.8 & .1 & 80.2 & .1 & 96.4 & & \\
\hline .2 & 22.5 & .2 & 81.2 & .2 & 96.5 & & \\
\hline .3 & 23.2 & .3 & 82.2 & .3 & 96.6 & & \\
\hline .4 & 24.0 & .4 & 83.1 & .4 & 96.7 & & \\
\hline .5 & 24.8 & .5 & 84.0 & .5 & 96.8 & & \\
\hline .6 & 25.6 & .6 & 84.8 & .6 & 96.9 & & \\
\hline .7 & 26.4 & .7 & 85.3 & .7 & 97.0 & & \\
\hline .8 & 27.2 & .8 & 86.1 & .8 & 97.1 & & \\
\hline .9 & 28.0 & .9 & 86.7 & .9 & 97.2 & & \\
\hline 5.0 & 28.9 & 9.0 & 87.2 & 13.0 & 97.3 & & \\
\hline .1 & 29.3 & .1 & 87.8 & .1 & 97.4 & & \\
\hline .2 & 30.5 & .2 & 88.3 & .2 & 97.5 & & \\
\hline .3 & 31.3 & .3 & 88.8 & .3 & 97.6 & & \\
\hline .4 & 32.1 & .4 & 89.3 & .4 & 97.7 & & \\
\hline .5 & 33.0 & .5 & 89.8 & .5 & 97.8 & & \\
\hline .6 & 34.0 & .6 & 90.2 & .6 & 98.0 & & \\
\hline .7 & 35.0 & .7 & 90.7 & .7 & 98.1 & & \\
\hline .8 & 36.0 & .8 & 91.1 & .8 & 98.2 & & \\
\hline .9 & 37.0 & .9 & 91.4 & .9 & 98.3 & & \\
\hline 6.0 & 38.0 & 10.0 & 91.8 & 14.0 & 98.3 & & \\
\hline .1 & 39.1 & .1 & 92.1 & .1 & 98.4 & & \\
\hline .2 & 40.2 & .2 & 92.3 & .2 & 98.5 & & \\
\hline .3 & 41.3 & .3 & 92.6 & .3 & 98.6 & & \\
\hline .4 & 42.5 & .4 & 92.9 & .4 & 98.7 & & \\
\hline .5 & 43.9 & .5 & 93.2 & .5 & 98.8 & & \\
\hline .6 & 45.2 & .6 & 93.5 & .6 & 98.9 & & \\
\hline & & & & & & & \\
\hline
\end{tabular}




\begin{tabular}{|l|l|l|l|l|l|l|l|}
\hline .7 & 46.7 & .7 & 93.7 & .7 & 99.0 & & \\
\hline .8 & 48.0 & .8 & 94.0 & .8 & 99.1 & & \\
\hline .9 & 49.5 & .9 & 94.2 & .9 & 99.1 & & \\
\hline
\end{tabular}

\section{Result}

In this study $23.3 \%$ of males showed E stage of CCS and stage II of CVM, $16.6 \%$ showed F stage of CCS and stage III of CVM, $13.3 \%$ showed stage G of CCS and Stage III of CVM, $8.3 \%$ showed stage G of CCS and stage IV of CVM, $11.67 \%$ showed $\mathrm{H}$ stage of CCS and stage IV of CVM (Table 4). Graph 1 depicted that E stage was mainly seen with CVM II, F stage was mainly seen with CVM III, G stage was mainly seen with CVM III, H stage was mainly seen with CVM IV
Whereas, $13.3 \%$ of females showed E stage of CCS and stage II of CVM, $13.3 \%$ showed F stage of CCS and stage III of CVM, $16.67 \%$ showed stage G of CCS and Stage III of CVM, $15 \%$ showed stage G of CCS and stage IV of CVM, $18.3 \%$ showed $\mathrm{H}$ stage of CCS and stage IV of CVM and $11.6 \%$ showed $\mathrm{H}$ stage of CCS and stage IV of CVM (Table 5). Graph 2 depicted that the E stage was mainly seen with CVM II, F stage was mainly seen with CVM III, G stage was mainly seen with CVM IV, H stage was mainly seen with CVM V

Correlation between Chronological age, CVM and CCS in males and females are shown in Table 6 and Table 7.

Table 4: Frequency of canine calcification at different cervical vertebrae stages in 8-14 year old males (CCS * CVM Cross tabulation)

\begin{tabular}{|l|c|c|c|c|c|c|c|}
\hline & & & CVM & & & & Total \\
\hline & & & I & II & III & IV & \\
\hline CCS & D & Count & 1 & 1 & & & 2 \\
\hline & & $\%$ within CCS & $50.0 \%$ & $50.0 \%$ & & & $100.0 \%$ \\
\hline & $\mathrm{E}$ & Count & 3 & 14 & 3 & & 20 \\
\hline & & $\%$ within CCS & $15.0 \%$ & $70.0 \%$ & $15.0 \%$ & & $100.0 \%$ \\
\hline & $\mathrm{F}$ & Count & & 6 & 10 & & 16 \\
\hline & & $\%$ within CCS & & $37.5 \%$ & $62.5 \%$ & & $100.0 \%$ \\
\hline & $\mathrm{G}$ & Count & & & 8 & 5 & 13 \\
\hline & & $\%$ within CCS & & & $61.5 \%$ & $38.5 \%$ & $100.0 \%$ \\
\hline & $\mathrm{H}$ & Count & & & 2 & 7 & 9 \\
\hline & & $\%$ within CCS & & & $22.2 \%$ & $77.8 \%$ & $100.0 \%$ \\
\hline Total & & Count & 4 & 21 & 23 & 12 & 60 \\
\hline & & $\%$ within CCS & $6.7 \%$ & $35.0 \%$ & $38.3 \%$ & $20.0 \%$ & $100.0 \%$ \\
\hline
\end{tabular}

Chi-Square Tests

\begin{tabular}{|l|l|l|l|}
\hline & Value & df & P \\
\hline Pearson Chi-Square & $58.425(\mathrm{a})$ & 12 & .000 \\
\hline
\end{tabular}

Table 5: Frequency of canine calcification at different cervical vertebrae stages in 8-14 year old females (CCS * CVM Cross tabulation)

\begin{tabular}{|l|l|c|c|c|c|c|c|}
\hline & & & CVM & & & & Total \\
\hline & & & II & III & IV & V & \\
\hline CCS & D & Count & 1 & & & & 1 \\
\hline & & $\%$ within CCS & $100.0 \%$ & & & & $100.0 \%$ \\
\hline & E & Count & 8 & 2 & & & 10 \\
\hline & & $\%$ within CCS & $80.0 \%$ & $20.0 \%$ & & & $100.0 \%$ \\
\hline & F & Count & 3 & 8 & & & 11 \\
\hline & & $\%$ within CCS & $27.3 \%$ & $72.7 \%$ & & & $100.0 \%$ \\
\hline & $\mathrm{G}$ & Count & 1 & 10 & 9 & & 20 \\
\hline & & $\%$ within CCS & $5.0 \%$ & $50.0 \%$ & $45.0 \%$ & & $100.0 \%$ \\
\hline & $\mathrm{H}$ & Count & & & 11 & 7 & 18 \\
\hline & & $\%$ within CCS & & & $61.1 \%$ & $38.9 \%$ & $100.0 \%$ \\
\hline Total & & Count & 13 & 20 & 20 & 7 & 60 \\
\hline & & $\%$ within CCS & $21.7 \%$ & $33.3 \%$ & $33.3 \%$ & $11.7 \%$ & $100.0 \%$ \\
\hline
\end{tabular}


Chi-Square Tests

\begin{tabular}{|l|l|l|l|}
\hline & Value & df & $p$ \\
\hline Pearson Chi-Square & $67.465(a)$ & 12 & .000 \\
\hline
\end{tabular}

a 16 cells $(80.0 \%)$ have expected count less than 5 . The minimum expected count is .12 .

Table 6: Correlation between Chronological age, CVM and CCS in males (Correlations Male)

\begin{tabular}{|l|c|c|c|c|}
\hline & & Age & CVM & CCS \\
\hline Age & Pearson Correlation & 1.000 & $.779 * *$ & $.853^{* *}$ \\
\hline & $\mathrm{P}$ &. & .000 & .000 \\
\hline & $\mathrm{N}$ & 60 & 60 & 60 \\
\hline CVM & Pearson Correlation & $.779^{* *}$ & 1.000 & $.810^{* *}$ \\
\hline & $\mathrm{P}$ & .000 &. & .000 \\
\hline & $\mathrm{N}$ & 60 & 60 & 60 \\
\hline $\mathrm{CCS}$ & Pearson Correlation & $.853^{* *}$ & $.810^{* *}$ & 1.000 \\
\hline & $\mathrm{P}$ & .000 & .000 &. \\
\hline & $\mathrm{N}$ & 60 & 60 & 60 \\
\hline
\end{tabular}

$* *$ Correlation is significant at the 0.01 level (2-tailed).

Table 7: Correlation between Chronological age, CVM and CCS in females (Correlations Female)

\begin{tabular}{|l|c|c|c|c|}
\hline & & Age & CVM & CCS \\
\hline Age & Pearson Correlation & 1.000 & $.748^{* *}$ & $.819^{* *}$ \\
\hline & $\mathrm{P}$ &. & .000 & .000 \\
\hline & $\mathrm{N}$ & 60 & 60 & 60 \\
\hline CVM & Pearson Correlation & $.748^{* *}$ & 1.000 & $.836^{* *}$ \\
\hline & $\mathrm{P}$ & .000 &. & .000 \\
\hline CCS & $\mathrm{N}$ & 60 & 60 & 60 \\
\hline & Pearson Correlation & $.819^{* *}$ & $.836^{* *}$ & 1.000 \\
\hline & $\mathrm{P}$ & .000 & .000 &. \\
\hline & $\mathrm{N}$ & 60 & 60 & 60 \\
\hline
\end{tabular}

**Correlation is significant at the 0.01 level (2-tailed).

Graph 1: Frequency of canine calcification at different cervical vertebrae stages in 8-14 year old males

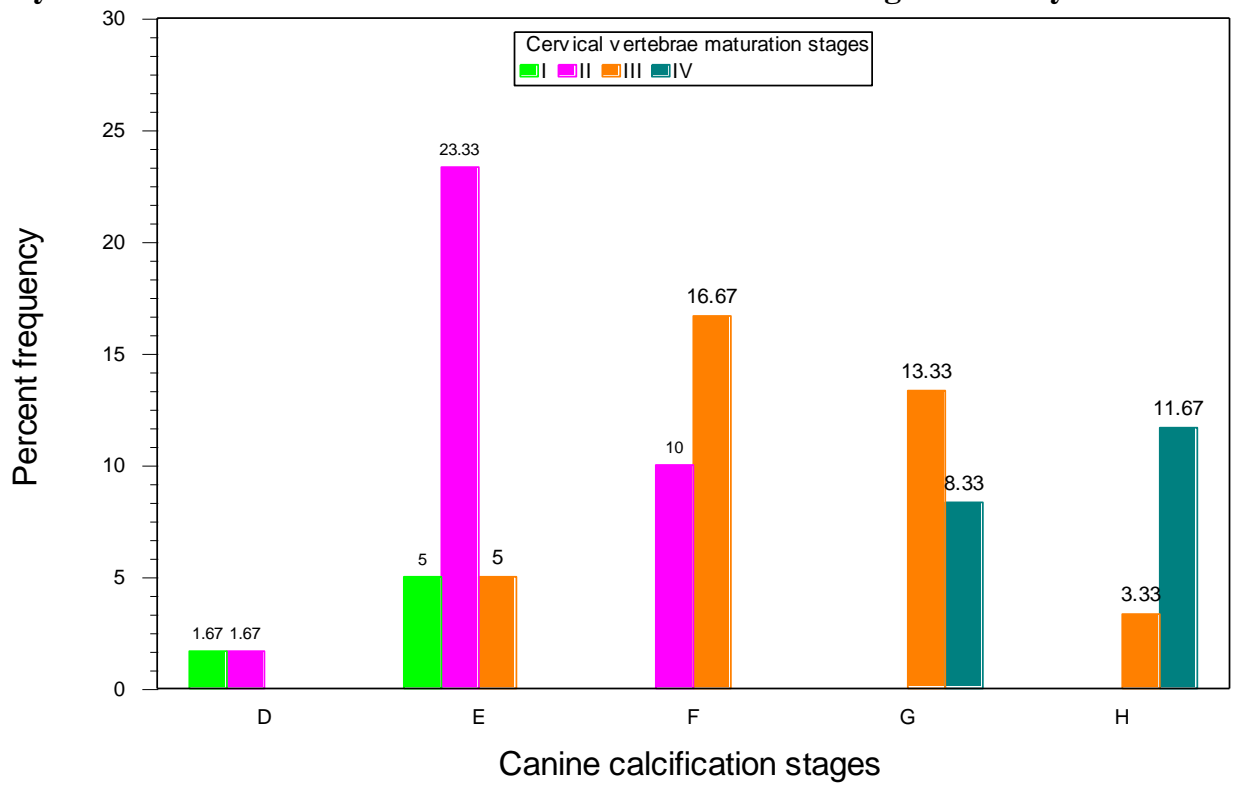


Graph 2: Frequency of canine calcification at different cervical vertebrae stages in 8-14 year old females

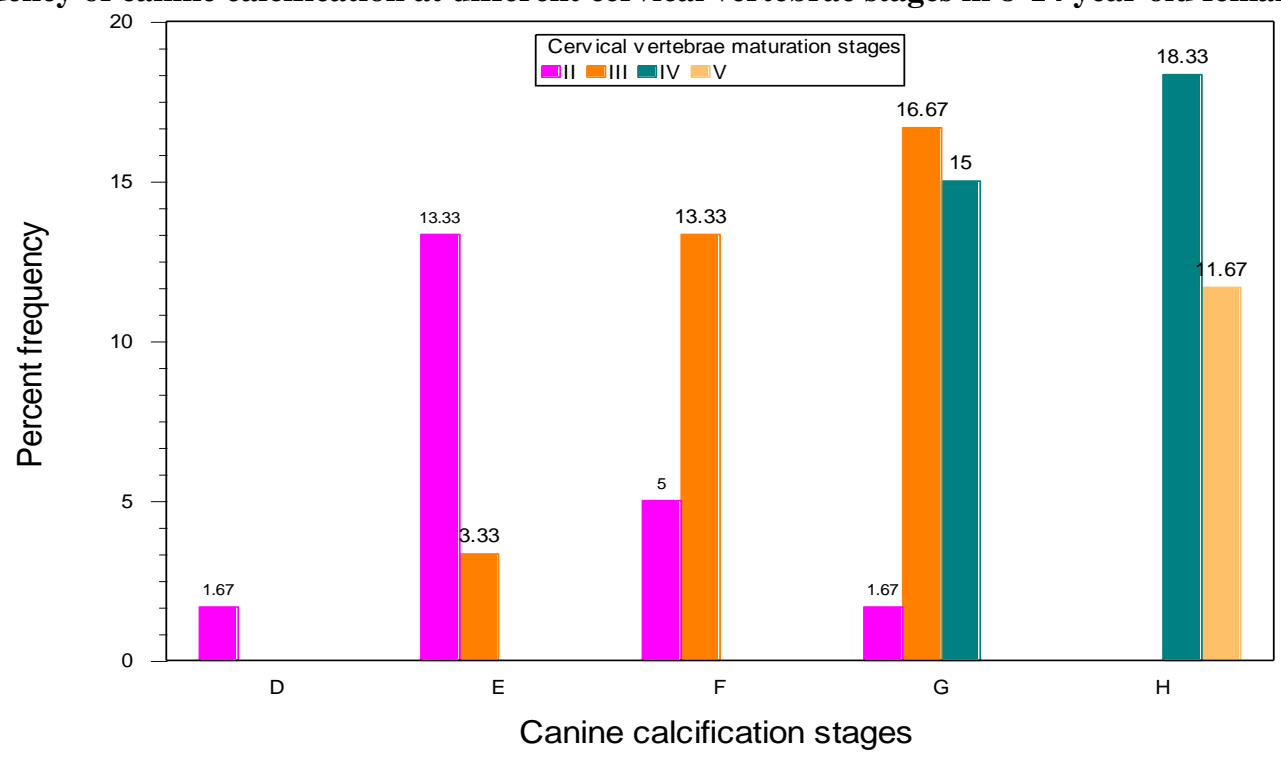

Fig. 1: CVMI
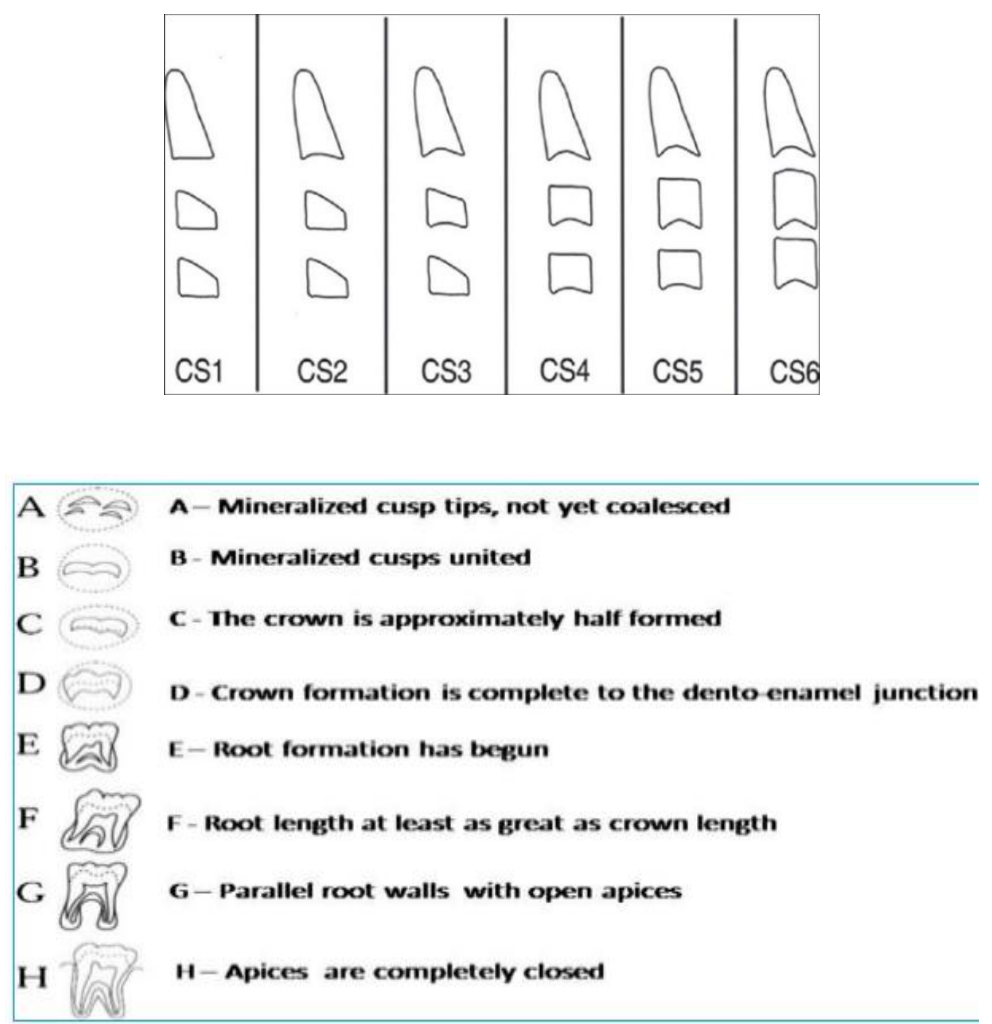

Fig. 2: Demirijan Index of dental age assessment

\section{Discussion}

This study combined the observation of the changes in the CVM and canine calcification during their maturation. The observation of Lamparski ${ }^{4} \&$ Bacetti, Franchi and Mc Namara ${ }^{6}$ were confirmed as the shapes of cervical vertebrae were seen to differ at each level of skeletal development. This provided a means by which we can determine the skeletal maturity of a person and thereby determine whether the possibility of potential growth existed. The shapes of vertebral bodies of $\mathrm{C} 2, \mathrm{C} 3$ and $\mathrm{C} 4$ changed from wedge shape to rectangular then to square along with greater in dimension vertically than horizontally as skeletal maturity progressed as correlated with our study also. The inferior borders were flat when most immature and they were concave when mature. The curvatures of the inferior vertebral borders were seen to appear sequentially from $\mathrm{C} 2$ to $\mathrm{C} 3$ to $\mathrm{C} 4$ as the skeletal matured. The concavities became more distinct as the person matured. Peak in mandibular growth occurs between CVMS II and CVMS III and CVMS $\mathrm{V}$ is seen two years after the peak. This findings are in correlation with our study. 
Studies conducted by Chertkow $(1979,1980),{ }^{8,9}$ Sierra (1987), ${ }^{10}$ Coutino et al $(1993)^{7}$ and Krailassiri $(2002)^{11}$ have indicated a strong relationship between mandibular canine and skeletal maturity indicators.

In the present study stages of canine calcification given by Demerijan ${ }^{1}$ et al (Stage D, E, F, G, H) were correlated with the stages of skeletal maturity (CVM stages I, II, III, $\mathrm{IV}, \mathrm{V})$ indicators given by Bacetti, Franchi and $\mathrm{Mc}$ Namara. ${ }^{6}$

In present study the chronological age for males in relation to mandibular canine in Stage E was 8.5-9.5yrs, Stage F- 10.5-11-5yrs, Stage G- 12.5- 13.5 yrs, Stage H 13.5 onwards. For females chronological age for mandibular canine in stage $\mathrm{E}$ was 8.5 , stage F- 9.5 yrs, stage G- 10.511.5yrs and stage $\mathrm{H}-12.5-13.5 y$ rs. And for males in relation to cervical vertebrae in Stage I was-8.5yrs, Stage II was 8.5-10.5yrs, Stage III was 11.5-13.5yrs, Stage 1V-13.5 own wards. For females Stage I was absent in our groups, Stage II- 8.5-9.5yrs, Stage III- 10.5-11.5yrs, Stage IV12.5yrs, Stage V -13.5 onwards.

Based on the observation of the present study attaining of maturity in canine calcification and cervical vertebrae maturational stages was ahead in females when compared to that of males. In this study F Stage denotes the pre-pubertal growth phase and G Stage is indicative of Peak high velocity. This figures are similar to the observation made by coutino $\mathrm{S}$ et al in 1993 . $^{7}$

The high association found in this study might be related to the use of the mandibular canine rather than a composite of dental units. From the findings of the present study the relationship between mandibular canine calcification stages and CVM stages may allow the clinician to more easily identify the stages of skeletal maturity from the Intral Oral Periapical radiograph and lateral cephalogram without resorting to the hand-wrist radiographs. ${ }^{12}$

Mandibular canine calcification stage could serve as a simple first level diagnostic tests to determine whether additional more sensitive, measures of maturity are warranted.

Limitation of this study being that there are many modern advancement like serum immunoglobin which can be used as skeletal maturity indicators and are more reliable then the canine calcification stages so, there is further scope of study including the modern techniques to assess the skeletal maturity indicators as well as their effect on different genders.

\section{Conclusion}

The results of this study suggested that there is high correlation between the Chronological age, dental calcification stages and cervical vertebrae maturation method and the observation showed that maturity in canine calcification and cervical vertebrae maturational stages was ahead in females when compared to males in this study. The Demirjian's ${ }^{1}$ methods for canine calcification stages and Baccetti, Franchi and Mc Namara ${ }^{5}$ method for cervical vertebrae maturation can be considered as efficient procedures and present the advantage of using Intra oral periapical radiographs and lateral cephalograms (part of basic record for orthodontic diagnosis) for estimation of skeletal maturation. There is high correlation/relationship between the canine calcification \& cervical vertebrae maturity. ${ }^{13}$ One can deduce from the present study the maturational status both dental \& skeletal at a certain chronological age of a patient. The study thus provides evidence that intra oral periapical radiographs and cephalometric radiographs can be used for assessing the maturation of an individual with a degree of confidence similar to other indicators such as the hand-wrist radiographs.

\section{Conflict of Interest: None.}

\section{References}

1. Demirjian A, Goldstein H, Tanner JM. A new system of dental age assessment. Human Biology. 1973;45(2):211-227.

2. Anderson DL, Thompson GW, Popovich F. Age of attainment of mineralization stages of the permanent dentition. J Forensic Sci. 1976;21:191-2000.

3. Carlos Flores-Mir C, Brian Nebbe, Paul W Major Use of skeletal maturation based on hand- wrist radiographic analysis as a predictor of facial growth: A systematic review. Angle Orthod. 2004;74(1):118-124.

4. Lamparski DG. Skeletal age assessment utilizing cervical vertebrae. M.S. thesis, University of Pittsburgh, 1972.

5. Hassel B, Farman AG. Skeletal maturation evaluation using cervical vertebrae. Am J Orthod Dentofac Orthop. 1995;107(1):58-66.

6. Baccetti T, Franchi L, McNamara JA Jr. An improved version of the cervical vertebral maturation (CVM) method for the assessment of mandibular growth. Angle Orthod. 2002;72:31623.

7. Coutinho S, Buschang PH, Miranda F. Relationships between mandibular canine calcification stages and skeletal maturity. Am J Orthod Dentofac Orthop. 1993;104(3):262-268.

8. Seymour Chertkow, Fatli P. The relationship between tooth mineralization and early radiographic evidence of the ulnar sesamoid. Angle Orthod. 1979;49(4):282-288

9. Seymour Chertkow. Tooth mineralizationas an indicator of the pubertal growth spurt. Am J Orthod. 1980;77:79-91.

10. Alicia M. Sierra. Assesment of Dental and Skelatal maturity Angle Orthod. 1987:194-208.

11. Krailassiri S, Anuwongnukroh N, Dechkunakorm S. Relationships between dental calcification stages and skeletal maturity indicators in Thai individuals. Angle Orthod. 2002;72(2):155-166.

12. Giri, J., Shrestha, B. K., Yadav, R., \& Ghimire, T. R. (2016). Assessment of skeletal maturation with permanent mandibular second molar calcification stages among a group of Nepalese orthodontic patients. Clin Cosmet Investig Dent. 2016;8:57-62. http://doi.org/10.2147/CCIDE.S93561

13. Sushil Kumar. Maxillary Canine as Skeletal Maturity Indicator. J Clin Diagn Res. 2017;11(5):ZC13-ZC16.

How to cite this article: Rohmetra A, Jaiswal A, Ishita,
Gupta N, Kulshrestha R. Evaluation of relationship
between chronological age cervical vertebrae maturation
index method and canine calcification stages for the
assessment of optimal treatment timing in orthodontic
patients. Int J Oral Health Dent. $2018 ; 4(4): 214-221$.

